\title{
Article
}

\section{Why do individuals seek out adventure sport coaching?}

\author{
Eastabrook, Chris and Collins, Loel \\ Available at http://clok.uclan.ac.uk/29406/ \\ Eastabrook, Chris ORCID: 0000-0003-0697-8002 and Collins, Loel ORCID: \\ 0000-0002-7478-1140 (2020) Why do individuals seek out adventure sport \\ coaching? Journal of Adventure Education and Outdoor Learning, 20 (3). pp. \\ 245-258. ISSN 1472-9679
}

It is advisable to refer to the publisher's version if you intend to cite from the work. http://dx.doi.org/10.1080/14729679.2019.1660192

For more information about UCLan's research in this area go to http://www.uclan.ac.uk/researchgroups/ and search for < name of research Group>.

For information about Research generally at UCLan please go to http://www.uclan.ac.uk/research/

All outputs in CLoK are protected by Intellectual Property Rights law, including Copyright law. Copyright, IPR and Moral Rights for the works on this site are retained by the individual authors and/or other copyright owners. Terms and conditions for use of this material are defined in the policies page.

\section{CLoK}

Central Lancashire online Knowledge www.clok.uclan.ac.uk

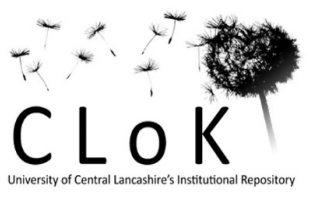




\section{Why do individuals seek out adventure sport coaching?}

Chris Eastabrook* and Loel Collins

+Institute for Coaching and Performance, University of Central Lancashire, Preston, UK

*Correspondence concerning this article should be addressed to Chris Eastabrook, Institute for Coaching and Performance, University of Central Lancashire, Preston, UK, PR1 2HE. CEastabrook@uclan.ac.uk 


\section{Why do individuals seek out adventure sport coaching?}

Individualisation is a key aspect of coaching practice. This is particularly important for adventure sport coaches, given the demands of the hyper-dynamic coaching environment and the various motivations to participate in adventure sports. However, the literature on individualisation is limited. As a logical beginning, the aim of this study is to understand why individuals seek coaching in the context of adventure sports. Semi-structured interviews with adventure sport clients $(\mathrm{N}=15)$ were thematically analysed, revealing that clients seek three different but not mutually exclusive experiences: holistic, authentic, and developmental. Importantly, the extent to which each experience was desired varied between individuals. These differences in individual desires place a fundamental emphasis on coaches' understanding of why an individual seeks coaching as well as their longer-term participation goals, and then having the adaptive expertise to meet those expectations. Further research is required to understand how aspects of the developmental experience are achieved, specifically in the desired contexts.

Keywords: adaptive expertise; adventure sports; adventure sport coaching; individualisation 


\section{Introduction}

The capacity to individualise lies at the heart of effective coaching (Garman, Whiston \& Zlatoper, 2000; Ives, 2008; Kim, Penney, Cho, \& Choi, 2006; Siedentop, Hastie, \& Van der Mars, 2011). Indeed, Ives (2008) identified individualisation, a process whereby a coach alters their practice in response to an individual, as one of nine aspects common to all coaching. Increasingly, authors have identified epistemological beliefs and coaching practices among high-level adventure sport coaches, which place individuals at the centre of the coaching process (Brymer, 2010; Christian, Berry \& Kearney, 2017; D. Collins, Collins \& Carson, 2016; L. Collins \& Collins, 2015, 2016b; L. Collins, Collins \& Grecic, 2015; Gray \& Collins, 2016). There remains little empirical evidence, however, on individualisation as an aspect of coaching behaviour in adventure sports. It is thus reasonable to examine why participants seek adventure sport coaching, and what those individuals want from their coaching. Such an investigation would expand knowledge on adventure sport coaching practice. Adventure sports form a significant subset of sport and recreation, one that is experiencing worldwide growth as participants increasingly seek interaction with the wilderness in addition to the thrill of the activity (Perdomo, 2014) and the strong social bonds that can be formed. The context of this study is that adventure sport coaching has features in common with Jones' (2006) description of coaching as an educative process at all levels rather than only for elite performance development (see De Bosscher \& Van Bottenburg, (2011)). As such, there is growing academic interest in adventure sport coaching practice, as well-trained, professional coaches rise to meet this demand. Therefore, in this paper we first consider individualisation as an aspect of effective coaching strategy before exploring its implications in an adventure sports context, and possible motivations to seek coaching. Finally, we ask: why do adventure sport participants seek coaching, and what do those clients want from their adventure sport coaching? 


\section{Individualisation in coaching}

According to Gearity (2012), a lack of individualisation is an aspect of poor coaching. Coaches have stressed the significance of individualisation (Greenwood, Davids, \& Renshaw, 2012) identifying physical, physiological, cognitive, and emotional characteristics that can be individualised. In particular, Greenwood et al. identified that an individualised approach allowed the emergence of a 'unique performance solution' (p. 419) that might suit diverse populations or activities without clear technical templates or models of performance. However, the literature on individualisation is sparse. Some evidence was presented by Sousa, Smith, and Cruz (2008), who reported that individualised goal-setting positively impacted athlete performance. Individualised feedback was described by Gould, Collins, Lauer, and Chung (2007) as an aspect of effective coaching strategy in experienced American football coaches. In terms of communication, Newell (1991) elaborated on the frequency, structure, nature, and quantity of feedback as aspects to individualise. In relation to goalsetting, Weinberg (1994) reported task characteristics, type of setting, difficulty, and degree of commitment as features that appeared individualistic, offering some guidance to coaches.

In addition, the learning process can be individualised. For example, Mosston and Ashworth's (2002) spectrum of teaching styles can be individualised based on pedagogic needs, where the spectrum ranges from coach-centred instructional styles to student-centred approaches with differing degrees of ownership of the learning by the learner. However, these styles are not without criticism or misuse. Sicilia-Camacho and Brown (2008) reported misapplication of Mosston and Ashworth's spectrum when focused on an individual teaching style, rather than aiming to 'exhibit mobility ability' (p. 92) with the teacher and student travelling along the spectrum of possible approaches as appropriate. The notion of learning styles (Pashler, McDaniel, Rohrer, \& Bjork, 2008) found in many National Governing Body (NGB) coach education manuals (see British Association of Snowsport Instructors, 2013; 
British Canoe Union, 2007; Mountain Training, 2013) can also be individualised. However, Franklin (2006) discussed the dangers of labelling a pupil as purely visual, audio or kinaesthetic, as this would neglect the nuances of teaching in a variety of contexts, subjects, or environments, and the broader demands of 'learnacy' (Claxton, 2002). Pashler et al. (2008) found no adequate evidence to justify incorporating learning styles assessments into general educational practice, contrary to the NGB coach education schemes. Individualisation is incorporated in the coaching process through differentiation of teaching delivery, an aspect identified by Collins and Collins (2015a, 2016b) in adventure sport coaching. Elements of style and content of delivery are tailored for the individual learner. However, we concur with Gould et al. (2012), who highlighted that more needed to be known about how and what coaches individualise.

\section{Individualisation in adventure sport coaching}

Individualisation is prized in high-level adventure sport coaching (Berry, Lomax, \& Hodgson, 2015). Christian et al. (2017) identified individualisation as a core belief of adventure sport coaching practice. Furthermore, Collins et al. (2015) and Collins and Collins (2015b) reported individualisation of the pedagogic needs of the individuals being coached in adventure sports. Individualisation also appears highly pertinent because of the impact of the hyper-dynamic, constantly changing environment (L. Collins \& Collins, 2016a). In addition, the personalised nature of adventure (Humberstone, 2009; Kerr \& Houge Mackenzie, 2012; Lynch \& Dibben, 2016; Houge Mackenzie \& Brymer, 2018) adds an extra dimension that could be individualised. Coaches must pitch each activity to align with individuals' personal construct for 'adventure'. Given the importance placed on individualisation as well as the highly personalised nature of adventure, it is appropriate that adventure sport coaches must consider what clients want from the coaching experience. 


\section{Possible motivations to seek out adventure sport coaching}

Some views of sport coaching have suggested that coaching attempts to improve performance by refining existing and well-established skills (Bale \& Sang, 1996; Carson \& Collins, 2011; Ericsson, Krampe, \& Tesch-Römer, 1993). In traditional sporting contexts, performance can be measured as victory over an opponent or faster times (Cassidy, Jones, \& Potrac, 2009; Gould et al., 2007; Ong, Elliott, Ackland, \& Lyttle, 2006). Miller and Kerr (2002) recognised the need to acknowledge motivations for participation beyond the pursuit of medals and victory. According to Vallerand (2004), 'motivation represents one of the most important variables in sport' (p. 427). In an adventure sports context, Brymer and Gray (2009) highlighted that participation was about harmony between participant and environment. However, this was only one perspective, from veteran participants. Kerr and Houge Mackenzie (2012) characterised participation in adventure sports more broadly, as complex and multifaceted. They suggested that an individualised approach to understanding participation might be required, echoing Collins and Brymer's (2018) notion of having a personalised conception of nature sports (akin to adventure sports). Coaching that does not reflect the culture of a particular sport may also be rejected (see Ojala \& Thorpe's study of elite snowboarders, 2015). It seems likely that this is a rejection of poor coaching rather than of all coaching (D. Collins, Collins \& Willmott, 2016). In short, the rejection of coaching represents a failure to individualise the process.

Bailey et al. (2010) offered potential reasons for participation, including elite referenced excellence (i.e. I am the best in X); personally referenced excellence (i.e. I am getting better than I was at Y); or participation for personal well-being (i.e. I do Z because I enjoy it and it makes me feel good). The elite referenced excellence category includes those who are motivated to be the first person among their peers to achieve a given accomplishment (first ascents and first descents may be specific to adventure sports - for 
example, a new river or climbing route). Those adventurers who seek out a coach to help them 'push their grade' or perform in more adventurous settings can be categorised in the personally referenced excellence grouping. Finally, personal well-being, to maintain or improve elements of physical fitness and the 'stay in shape' factor, is shared by many sports. However, increased use of the outdoors for this purpose should be recognised. In addition, the 'cathartic process' of adventure and challenge is recognised by many cultures and provides a possible motivation that falls into the final category. In particular, accommodating the shifts between these three broad categories throughout an athlete's lifetime would suggest that experience and age may also affect individualisation. Brymer and Gray (2009) recognised these changes in adventure sports, and suggested that they were aspects that could be individualised.

Other perspectives on motivation to seek coaching have offered a more holistic view of coaching. Super, Verkooijen, and Koelen (2018) reported that community sport coaches were teaching 'life skills' to vulnerable young people. Such coaching was focusing on cooperation, sportsmanship, and health rather than on level of performance. This approach may resonate with adventure sport coaching because of its outdoor education antecedents (L. Collins \& Collins, 2016a), in which the activity is a means to teach wider education themes once basic movement skills to access the outdoors are established (Priest \& Gass, 2005). The transfer of wider education themes or life skills through any sport coaching should not be considered automatic, since 'training coaches to transfer these skills from the sport setting is a necessary next step in coach training research' (Vella, Oades, \& Crowe, 2011, p. 45). The debate about whether these themes, such as confidence and character, are best taught implicitly or explicitly (Turnnidge, Côté, \& Hancock, 2014) may hinge on the context of the coaching. In this context, perhaps a difference between the outdoor educator and the adventure sport coach is the degree of explicitness. The outdoor educator's goal may be the 
explicit development of these themes to aid wider education, but an implicit approach is necessary for the adventure sport coach, who must address such themes to achieve the client's desired level of performance or participation. If this is true, the role of the adventure sport coach combines the complexity of outdoor education with that of skill development. This echoes Valkonen, Huilaja, and Koikkalainen (2013), who proposed that a well-trained outdoor professional was required to facilitate experiences in adventurous activities. Logically, the ability to tailor the experience to the individual would be central to their practice and a focus of training. Situational awareness and comprehension of the associated situational demands inform coaches' actions and enable them to meet individuals' needs. It is therefore fundamental to adventure sport coaching practice that coaches know why adventure sport participants seek coaching and what these participants want from their coaching experience. This inquiry is investigated in the current paper.

\section{Methodology}

An inductive, qualitative approach was used to investigate why clients seek coaching and what they want from those experiences. To promote breadth and richness of responses, semi-structured interviews were conducted with a sample of adventure sport participants who had sought coaching at a large, established commercial provider of adventure sport coaching.

\section{Participants and procedure}

Stratified-random sampling (Robson, 2011) was employed to gain a representative sample ( $\mathrm{N}=15)$. Participants were selected using the following inclusion criteria: (1) an adventure sport participant, (2) undertaking a five-day adventure sport coaching programme, for either mountain- or water-based adventure sports (3) an openness and willingness to engage in the research. Stratification was employed to reflect gender (female, $n=6$, male, $n=$ 9) as well as characterisation of adventure sports (mountain based $(n=11)$ or water based (n 
=4)) (see Table 1). This stratification was typical of the adventure sport coaching provider in question. Pseudonyms have been used for the purposes of this study, to maintain anonymity.

\section{Insert Table 1 close to this point}

Interviews were conducted over the autumn, winter and spring of 2017/18, to ensure a range of activities and participants. Participants were initially invited to participate at the start of their course and were provided with an information sheet and consent form midway through the course if they expressed an interest in participating. The interviews were then conducted either face-to-face in a comfortable and convenient location agreed to by the participants (Whiting, 2008), or via Skype (Deakin \& Wakefield, 2014), 48 hours after the course had ended. Interviews were guided by the questioning and prompts outlined in Table 2 , to focus on the motivations and expectations of the participant when seeking coaching. All interviews were digitally recorded in $\mathrm{mp} 3$ format. The study was conducted in accordance with the approval of the University of Central Lancashire's BHASS Ethics Committee.

\section{Insert Table 2 close to this point}

\section{Data processing and analysis}

Interviews were transcribed verbatim and reviewed for accuracy against the digital recording (Braun \& Clarke, 2006; Fereday \& Muir-Cochrane, 2006). A hybrid thematic analysis, both inductive and deductive, was used to interpret the data (Fereday \& MuirCochrane, 2006), allowing it to be compared with existing concepts whilst remaining open to recognising new themes and interpreting themes anew (Braun \& Clarke, 2012). The transcripts were codified whilst listening to the original recordings (Smith, Larkin, \& Flowers, 2009, p. 82). Lower-, mid-, and higher-order themes were identified using NVivo 11. The significance of themes was not only indicated by frequency but also by significance 
and emphasis during the interview, derived from the annotations made in the initial readings and interview field notes.

To guard against researcher bias and improve trustworthiness, bracketing (Morrow, 2005) was utilised in the form of a reflexive journal (Davis \& Meyer, 2009), which was maintained throughout data collection and analysis. Additionally, internal member checking (Lincoln \& Guba, 2005) was conducted during the interviews to check for accuracy, consistency, integrity, and grounding of data without influencing the responses of interviewees. External member checking between the first and second authors was achieved via a joint analysis of the data, repeated questioning and interpretation of the themes and their meanings until a final interpretation was agreed upon.

\section{Results and Discussion}

Fifteen adventure sport coaching clients aged between 25 to 56 years old were interviewed. Interview duration ranged from 11 to 25 minutes. Analysis of the transcripts generated 1003 codified units from the transcripts. The main thematic analysis was grouped into 75 lower-order themes, 14 mid-order themes and three higher-order themes: holistic, authentic, and developmental experiences (see Table 3). Below, the higher-order themes are considered in relation to the main focus of this investigation.

\section{Insert Table 3 close to this point}

\section{Holistic experience}

Three mid-order themes, domestic, social, and package, contribute to the holistic experience and are important considerations for those seeking coaching. Regarding the domestic aspects, 14 interviewees expressed a desire to have high quality arrangements on the course, which had been fulfilled. Kyle said, 'It's nice they have good accommodation and food'. Jodi added, 'The food here is amazing ... it's all part of it', suggesting that satisfying 
domestic aspects were part of the whole experience. Good quality domestic arrangements included time with a community of fellow adventure sport participants. The social interaction was highly valued and viewed as an aspect of the experience. Emma described this as, 'chatting to other people, both on [her] particular course and those engaged on other courses'. The shared bonds between participants generated by their experiences were recognised as significant by Houge Mackenzie and Brymer (2018), Varley and Semple (2015) and Williams and Soutar (2005).

Echoing Emma's comment, Justin further elaborated the social learning aspect by linking this explicitly to his learning:

I thought it was quite nice to be residential, so you have a bit more of an experience of it, feels like a holiday, a big course, feels like you are learning something, but now I'm here it's even better because you have such a breadth of experience from all the other people ... it's magnified it [the learning], made it much better.

Gina offered the insight: 'When you talk about things, you deconstruct things in a different way socially than you do between instructor and student'. This supports Ellmer and Rynne (2016), who reported in a biographical study of a single individual that social learning was a function of adventure sports. A further dimension of the social aspect is immersion in the culture surrounding the activity. Engaging in the coaching process offers entry into the lifestyle associated with each sport. Pierce, for example, derived enjoyment 'from just listening to the stories of the coach'. Extra-curricular activities that coaches may facilitate can influence clients' behaviour, engaging them or inducting them into the lifestyle surrounding the activity. Feeling like a climber or kayaker enhances clients' enjoyment, reflecting the lifestyle aspect of adventure sports. For example, after climbing at Tremadog, it is traditional to go for a cup of tea at the Eric Café, a venue steeped in history. For some participants, 
adventure sports could be considered a lifestyle, offering a sub-culture of which to be a part, self-realisation and personal identify, consistent with the definitions by Wheaton (2004) and Ellmer and Rynne (2016). While the differences between adventure sport, nature sport, action sport, and lifestyle sport may be of academic interest, such overlap, as highlighted by the interviewees, is clearly part of the sought-after adventure sport coaching experience.

Encapsulated in the packaged aspect is that of feeling safe whilst being in adventurous environments. Gina commented that: 'You might be putting yourself in a situation that's not acceptable', and Justin said: 'I wouldn't be doing this on my own at this point'. It was widely reported by interviewees that they perceived coaching as the safest option for them to have quality, safe 'outdoor' time. Offering a holistic, facilitated experience, where safety is paramount, links to Pine and Gilmore's (1998) notion of the experience economy and aspects of commodification. Multiple authors (Beames \& Varley, 2013; Brown, 2000; Loynes, 1998) warn that some benefits of outdoor education may be lost in the commodification process. However, it would seem that the commodification of some aspects of the coaching experience, in this context, is desirable. For example, where a coach might make the majority of the decisions about a particularly adventurous activity, or having access, as part of the course, to appropriate specialist equipment for an activity. The holistic experience acts as a scaffold and supports the authentic experience.

\section{Authentic experience}

A context-specific authenticity is central to the client experience. In this context, authenticity is how real the experience is to the client, echoing the relationship between client and experience, or learner and object, as reported by Bonnett and Cuypers (2002). The interviewees reported that the three dimensions - adventure, challenge, and context interacted and, when experienced together, created a sense of authenticity. Raymond's 
expectation was that the 'holiday' package was combined with his desire for 'real adventure'. Fourteen of the 15 interviewees expressed the importance of authenticity during their coaching, this appears highly individualised. This presents a challenge for coaches, who need to discern what clients find adventurous. The interviewees all reported that they wished to engage in authentic adventure as a participant, rather than as a passenger, who is at the centre of the activity. In this context, participants were able to understand the risks involved in the activity and to have some degree of ownership over the decisions governing their participation. As a passenger, one's experience is devoid of risk. The coach makes the decision, akin to Humberstone's (Humberstone, 2009) illustration and Brown's notion of passengers and partners (2000). The desire to be participants rather than passengers reflects an additional dimension that requires individualisation. Chloe's motivation was, in part, to experience the difficulties associated with adventure as she saw it. Raymond linked the desire for adventure to the learning experience:

I think if I didn't have the adventure, it would feel like a bit hermetic, a little bit, just theoretical rather than practical and actually the mountains are all about [the] practical side of things. You can do things in the classroom, I could do that anywhere but actually I've come here to climb mountains, yeah, for me the two things [learning and adventure] are intrinsic.

There was an expectation amongst 12 of the interviewees that adventure sport coaching should be both physically and cognitively challenging to be authentic, which, in parts, starts to clarify the nature of authenticity amongst these participants. Natalie echoed Raymond, articulating the nature of that challenge, 'it's important that you are probably challenged, to some degree, physically and intellectually, to learn'. The value placed on learning is implied in this quote. There is an implicit hedonistic aspect, the thrill or rush (Buckley, 2012) of overcoming both the physical and cognitive challenges. Such demands 
differentiate challenge from adventure. The challenge of completing a hard-climbing route indoors could be enjoyable, but the desire and reasons for seeking coaching lie in taking that newly realised skill outdoors. Natalie's attention to learning suggested that notions such as comfort zone (Priest \& Gass, 2005) and edgework (Lyng \& Snow, 1986; Lyng, 1990; Pomfret \& Bramwell, 2016) become aspects that demand individualisation. Learning through adventure sports clearly has to be authentic to the individual.

A sentiment common to all interviewees was the importance of context in the learning experience. Alexandre highlighted this, saying, 'Whilst it was the skill that had been coached, it was only when it was applied in the context of mountaineering that it really felt like I knew, felt real, felt like I knew the skill better'. Understanding and experiencing the context for the skill, and the situation for its application, was perceived as important. Establishing conceptual links, associations, honing perceptions and situational awareness contextualised the learning in the experience. The need for context may also reflect the learning of adults in this study as requiring an explicit relevance to the skills being learnt, andragogy (Knowles, 1970) rather than pedagogy. The extent to which this encourages the capacity of participants to learn independently requires further investigation. The nature of the contextual experience depends upon the individual and, in particular, their long-term goals in adventure sports. If coaching is to feel authentic for clients, coaches must first understand clients' participation in adventure sports and shape the learning environment accordingly. As authenticity is clearly personal, it represents an additional coaching aspect to individualise. Coaches must understand each client's concept of adventure, challenge, and context, and understand how the coaching fits with the clients' larger goals in order to effectively align themselves with clients and their experience.

\section{Developmental experience}


Development of confidence, technical skills and building capacity for independent performance and learning emerged as key aspects of the developmental experience. All interviewees discussed the importance of developing confidence as a specific aspect of development. Jodi's end goal was 'to become more confident'. Gina sought 'mainly confidence building'. Reflecting on her multiple coaching experiences, Chloe stated that the reason for this course was to 'get my confidence back and to make me enjoy it again'. It was unclear if the earlier coaching experiences had led to the fall in confidence. Chloe further highlighted, 'If you looked at the list of how much coaching I've had you'd think, gosh she'd be really good, and I don't feel that I am'. Confidence is a synergy and an outcome of the developmental experience. Clients seek greater confidence from their coaching but also have more confidence if the coaching experience is successful. In other words, confidence begets confidence.

Alexandre emphasised his confidence as an aspect of his independence: 'The confidence having had a coached experience then doing it on your own, [is] good for confidence'. Martin linked his desire for greater confidence more directly with consolidating technical performance: 'I think the confidence comes from practising'. All interviewees saw the value in practice and feedback with a coach present, this presumably included feedback contributing to their self-efficacy. Four interviewees also used the term 'confidence' to describe the increased self-belief sought through coaching. In particular, their coach was a key source of higher self-belief. Kyle related that '[the coach] showed me what I can achieve'. Tailoring any coaching practice towards developing confidence begins with understanding what the client means by confidence. Given how imprecisely it was described in these interviews, the process of developing athletes' confidence could represent a challenge for coaches. 
Six interviewees explicitly identified technical development as a goal of coaching. Marian characterised the nature of the desired skill retention: 'It was about embedding good techniques; the foundations are kinda there for future paddling'. Marian's description reflects the definition of learning advanced by Soderstrom and Bjork (2015), according to which skills are stored in the memory flexibly and adaptively. Gina explained the link between skill usage and context: 'Each time you have to adapt, it's fundamentally the same mental theory underneath but you have to learn to be flexible with it, apply it slightly differently in different situations'. Clearly, this cognitive aspect to the performance in adventure sports is important, perhaps reflecting the desire for independence. Several authors (Carson \& Collins, 2016; Christensen, Sutton, \& McIlwain, 2016) have proposed models of skill acquisition that include cognitive aspects. This challenges the notions of skilful performance without cognitive effort (see Dreyfus, 2004; Fitts \& Posner, 1967) that is used extensively in many NGB coach education programmes.

The desire for independence was one of the main drivers of adaptive and flexible personal skills. According to Martin, 'One of the reasons for doing it [coaching], would be to be more confident, more competent to go and actually do it on my own'. Similarly, Brett said: 'When I leave, it's to prepare me for [independent] adventures'. Both emphasised how coaching fitted within their larger long-term goals. Nine other interviewees cited independence as a motivation to seek coaching. However, like adventure, independence is personal. In the context of this study, the two appeared linked. Some clients performed independently on a coach-led activity, while others sought independence from coaches, postcoaching. Gina explained, 'I think I'd find it stressful doing it without having, effectively a good coach there', but she also wanted to be independent within the activity, citing her desire to be 'confident in finding my footing'. She essentially wanted to delegate critical decisionmaking to the coach. However, those seeking independence post-coaching recognised 
autonomous decision-making as part of their independent performance. Raymond highlighted the potential impact of being coached on decision-making: 'Good coaching will set you up for decision-making long into the future'.

Closely linked to decision-making abilities is the clients' capacity to learn from experiences. If coaches are to be successful in teaching independence, they must understand the degree to which clients want to be independent. Coaches must understand that clients can be independent on coach-led activities, i.e. choosing their own route or footing. Contrastingly, clients may want coaches to make decisions for a more adventurous experience, sacrificing their independence for a specific experience or goal. At other times they may want more control over the activity in preparation for their long-term development. This difference in potential desires for independence emphasises coaches' professional judgement and decision-making to individualise the degree of independence sought at any particular time in the coaching, and a sophisticated epistemology that is able to match clients' desires.

Pierce's comments reflected the value the interviewees placed on learning. 'I think if I stop learning I'll just give up on life; always keep learning, it's probably the greatest gift we can have'. In addition, Emma recognised the need for robust, well-practised personal skills that she could adapt to the range of environments she might encounter: 'I can learn those things here but I'm going to have to go away and practise them'. For Emma's practice to be effective, she needed to be able to make sense of the movement and the environment. Such learning ability allows the clients to make sense of novel experiences, to inform their future participation, independently of a coach. Clearly, individualising to facilitate client learning is common to all coaching; significant to the adventure sport coach, however, is the ability to prepare the client to learn on their own, post-coaching, linking the adventure sport coach's role to that of educators. 
The coaching role must cater for several, sometimes opposing demands. Clients want, in part, to be taken to the edge, having their authentic experience with their coach, but also want long-term learning that they can adapt independently to the hyper-dynamic environment. Pierce exemplified this by having a desire to be '.. taken into space beyond what you are capable yourself', but also did not 'want to rely on them [coaches], I want to feel confident in my own skills and ability'. Understanding the client's motivation for coaching and their long-term goals in adventure sports is clearly a precursor to balancing the demands placed on coaches. In addition, the relationship between long-term participation in adventure and reason to seek coaching gives coaches some insight into what clients might deem a successful performance in adventure sports. Essentially, coaches must understand how their coaching fits with clients' longer-term plans, contextualising the reason for the coaching. Furthermore, if that coaching is to be well received it should be individualised. This study has found four aspects of adventure sport coaching to be individualised: challenge, adventure, context, and independence. Critically, the authentic nature of the experience requires coaches to have a deep understanding of the environment, the activity and the individual.

\section{Limitations of the study and future research}

This research was conducted at a single centre in the UK and, therefore, aspects of the finding may be specific to that location. Further, a small representative sample was used. However, the research methodology achieves a high 'information power' (Malterud, Siersma \& Guassora, 2016) and therefore a lower sample size is appropriate. A broader, larger scale study may nevertheless enable different philosophical positions to be explored, particularly across different cultures. Specifically, regarding the developmental experience, the next logical question is to consider how coaches achieve these desires. Understanding what these 
strategies are, why they are used, and when they are used, could inform coach education in adventure sports.

\section{Conclusion}

The findings of this study suggest that clients seek adventure sport coaching for three different types of experience: holistic, authentic, and developmental, which are not mutually exclusive and are synergetic. Considering adventure sport coaching in this way further adds to the notion that coaching in this realm has more in common with education than with elite performance development. The adventure sport coaching experience has aspects in common with lifestyle sports, performance coaching and education, creating a complex set of circumstances for coaches to navigate if they are to be successful from the clients' perspective. Coaches are integral in aligning the activities on the coaching course with each client's expectations, which forms their personalised coaching experience. This, in part, explains why those interviewed could not separate the coach from the coaching. Additionally, individualisation appears to have greater breadth than originally conceived and places pressure on coaches to be adaptable, flexible, and innovative (Bowes \& Jones, 2006; Nash \& Collins, 2006; Tozer, Fazey, \& Fazey, 2007), transcending mere in-session pedagogy. A good adventure sport coach will need to adapt their practice to fulfil the needs and motivation of the client, and then have the flexibility to meet the client expectations of an authentic and developmental experience. These requirements for adaptability point towards the need to understand how coaches themselves can be developed to respond to the synergy of environmental and client demands. This coaching environment emphasises skilled, professional coaches with a sophisticated epistemological position and the tools to meet client expectation; this seems particularly challenging in adventure sports, where personal constructs of adventure are present throughout. These constructs affect the client's motivation for seeking coaching and therefore the level of performance desired. Clients may be looking 
for a short-term adventurous experience in the context of their long-term learning for independence and also wanting a commodified experience that facilitates participation postcoaching. The demands on the adventure sport coach are complex, contextual, and, at times, conflicting.

\section{Disclosure statement}

No potential conflict of interest is reported.

\section{References}

Bailey, R., Collins, D., Ford, P., MacNamara, A., Toms, M., \& Pearce, G. (2010). Participant development in sport: An academic review. Sports Coach UK, (June 2015), 1-134.

Bale, J., \& Sang, J. (1996). Culture, geography and global change. In Kenyan Running: Movement (pp. 156-158). London: rank Cass.

Beames, S., \& Varley, P. (2013). Eat, play, shop: The Disneyization of adventure. In S. Taylor, P. Varley, \& J. Tony (Eds.), Adventure tourism: Meanings, experience and learning (pp. 77-84). Oxford: Routledge.

Berry, M., Lomax, J., \& Hodgson, C. (2015). Adventure Sports Coaching. Oxford: Routledge.

Bonnett, M., \& Cuypers, S. (2002). Autonomy and authenticity in education., 326. In N. Blake, P. Smeyers, R. Smith, \& P. Standish (Eds.), The Blackwell guide to the Philosophy of Education (pp. 326-340). Oxford, UK.: Blackwell.

Bowes, I., \& Jones, R. L. (2006). Working at the edge of chaos: Understanding coaching as a complex, interpersonal system. The Sport Psychologist, 20(2), 235-245. https://doi.org/10.1123/tsp.20.2.235 
Braun, V., \& Clarke, V. (2006). Using thematic analysis in psychology. Qualitative Research in Psychology, 3(2), 77-101.

Braun, V., \& Clarke, V. (2012). Thematic analysis. In Cooper H (Ed.), APA handbook of research methods in psychology. (2nd ed.). American Psychological Association.

British Association of Snowsport Instructors. (2013). The BASI Manual - Alpine (Second Edi). British Association of Snowsport Instructors.

British Canoe Union. (2007). Coaching. In F. Ferrero (Ed.), British Canoe Union Coaching Handbook (pp. 7-48). Wales: Pesda Press.

Brown, H. (2000). Passengers, participants, partners and practitioners. Working with risk to empower groups. Horizon, 12, 37-39.

Brymer, E. (2010). Risk taking in extreme sports: A phenomenological perspective. Annals of Leisure Research, 13(1-2), 218-238. https://doi.org/10.1080/11745398.2010.9686845

Brymer, E., \& Gray, T. (2009). Dancing with nature: rhythm and harmony in extreme sport participation. Journal of Adventure Education \& Outdoor Learning, 9(2), 135-149. https://doi.org/10.1080/14729670903116912

Buckley, R. (2012). Rush as a key motivation in skilled adventure tourism : Resolving the risk recreation paradox. Tourism Management, 33(4), 961-970. https://doi.org/10.1016/j.tourman.2011.10.002

Carson, H. J., \& Collins, D. (2011). Refining and regaining skills in fixation/diversification stage performers: the Five-A Model. International Review of Sport and Exercise Psychology, 4(2), 146-167. https://doi.org/10.1080/1750984X.2011.613682

Carson, H. J., \& Collins, D. (2016). The fourth dimension: A motoric perspective on the anxiety-performance relationship. International Review of Sport and Exercise 
Psychology, 9858(November 2015), 1-21.

https://doi.org/10.1080/1750984X.2015.1072231

Cassidy, T., Jones, R. L., \& Potrac, P. (2009). Understanding sports coaching: the social, cultural and pedagogical foundations of coaching practice. Retrieved from http://books.google.com/books?id=y5CSj7OGn1gC

Christensen, W., Sutton, J., \& McIlwain, D. J. F. (2016). Cognition in skilled action : Meshed control and the varieties of skill experience. Mind \& Language, 31(1), 37-66.

Christian, E., Berry, M., \& Kearney, P. (2017). The identity, epistemology and developmental experiences of high-level adventure sports coaches. Journal of Adventure Education and Outdoor Learning, 17(4), 1-14. https://doi.org/10.1080/14729679.2017.1341326

Claxton, G. (2002). Building learning power. TLO Limited Bristol.

Collins, D., Collins, L., \& Carson, H. J. (2016). "If it feels right, do it": Intuitive decision making in a sample of high-level sport coaches. Frontiers in Psychology, 7(APR), 1-10. https://doi.org/10.3389/fpsyg.2016.00504

Collins, D., Collins, L., \& Willmott, T. (2016). Over egging the pudding ? Comments on Ojala and Thorpe. International Sport Coaching Journal, 3(1), 90-93. Retrieved from http://dx.doi.org/10.1123/iscj.2015-0068

Collins, L., \& Brymer, E. (2018). Understanding nature sports: A participant centred perspective and its implications for the design and facilitating of learning and performance. Annals of Leisure Research, $0(0), 1-16$. https://doi.org/10.1080/11745398.2018.1525302

Collins, L., \& Collins, D. (2015a). Integration of professional judgement and decision- 
making in high-level adventure sports coaching practice. Journal of Sports Sciences, 33(6), 622-633. https://doi.org/10.1080/02640414.2014.953980

Collins, L., \& Collins, D. (2015b). Professional judgement and decision-making in adventure sports coaching: the role of interaction. Journal of Sports Sciences, (January), 1-12. https://doi.org/10.1080/02640414.2014.953980

Collins, L., \& Collins, D. (2016). Challenges in adventure sports coaching. In B. Humberstone, H. Prince, \& K. A. Henderson (Eds.), Routledge International Handbook of Outdoor Studies. Oxford: Routledge. https://doi.org/10.4324/9781315768465.ch44

Collins, L., Collins, D., \& Grecic, D. (2015). The epistemological chain in high-level adventure sports coaches. Journal of Adventure Education and Outdoor Learning, 15(3), 224-238. https://doi.org/10.1080/14729679.2014.950592

Davis, N. W., \& Meyer, B. B. (2009). Qualitative data analysis: A procedural comparison. Journal of Applied Sport Psychology, 21(1), 116-124. https://doi.org/10.1080/10413200802575700

De Bosscher, V., \& Van Bottenburg, M. (2011). Elite for all, all for elite? An assessment of the impact of sports development on elite sport success. In B. Houlihan \& M. Green (Eds.), Routledge handbook of sports development (pp. 579-598). New York, NY: Routledge.

Deakin, H., \& Wakefield, K. (2014). Skype interviewing: reflections of two PhD researchers. Qualitative Research, 14(5), 603-616. https://doi.org/10.1177/1468794113488126

Dreyfus, S. E. (2004). The five-stage model of adult skill acquisition. Bulletin of Science, Technology and Society, 24(3), 177-181. https://doi.org/10.1177/0270467604264992

Ellmer, E., \& Rynne, S. (2016). Learning in action and adventure sports. Asia-Pacific Journal 
of Health, Sport \& Physical Education, 7(2), 107-119.

https://doi.org/10.1080/18377122.2016.1196111

Ericsson, K. A., Krampe, R. T., \& Tesch-Römer, C. (1993). The role of deliberate practice in the acquisition of expert performance. Psychological Review, 100(3), 363-406. https://doi.org/10.1037/0033-295X.100.3.363

Fereday, J., \& Muir-Cochrane, E. (2006). Demonstrating rigor using thematic analysis: A hybrid approach of inductive and deductive coding and theme development. International Journal of Qualitative Methods, 5(1), 80-92. https://doi.org/10.1063/1.2011295

Fitts, P. M., \& Posner, M. I. (1967). Human performance. Belmont, CA: Brooks/Cale.

Franklin, S. (2006). VAKing out learning styles —-why the notion of 'learning styles' is unhelpful to teachers. Education 3-13, 34(1), 81-87. https://doi.org/10.1080/03004270500507644

Garman, A. N., Whiston, D. L., \& Zlatoper, K. W. (2000). Media perceptions of executive coaching and the formal preparation of coaches. Consulting Psychology Journal, 52(3), 201-205. https://doi.org/10.1037/1061-4087.52.3.201

Gearity, B. T. (2012). Poor teaching by the coach: A phenomenological description from athletes' experience of poor coaching. Physical Education and Sport Pedagogy, 17(1), 79-96. https://doi.org/10.1080/17408989.2010.548061

Gould, D., Collins, K., Lauer, L., \& Chung, Y. (2007). Coaching life skills through football: A study of award winning high school coaches. Journal of Applied Sport Psychology, 19(1), 16-37. https://doi.org/10.1080/10413200601113786

Gray, P., \& Collins, D. (2016). The adventure sports coach: All show and no substance? 
Journal of Adventure Education and Outdoor Learning, 16(2), 160-171.

https://doi.org/10.1080/14729679.2015.1123163

Greenwood, D., Davids, K., \& Renshaw, I. (2012). How elite coaches' experiential knowledge might enhance empirical research on sport performance. International Journal of Sports Science and Coaching, 7(2), 427-429. https://doi.org/10.1260/17479541.7.2.427

Houge Mackenzie, S. H., \& Brymer, E. (2018). Conceptualizing adventurous nature sport: A positive psychology perspective. Annals of Leisure Research, $0(0), 1-13$. https://doi.org/10.1080/11745398.2018.1483733

Humberstone, B. (2009). Inside/outside the Western "Bubble": The nexus of adventure, adventure sports and perceptions of risk in UK and Mauritius. On the Edge Leisure Consumption and the Representation of Adventure Sports, (104), 1-14. https://doi.org/10.1016/j.scitotenv.2016.03.186

Ives, Y. (2008). What is 'coaching '? An exploration of conflicting paradigms. International Journal of Evidence Based Coaching and Mentoring, 6(2), 100-113. https://doi.org/http://ijebcm.brookes.ac.uk/documents/vol06issue2-paper-08.pdf

Jones, R. L. (2006). How can educational concepts inform sports coaching? In The sports coach as educator (pp. 21-31). Routledge.

Kerr, J. H., \& Houge Mackenzie, S. H. (2012). Multiple motives for participating in adventure sports. Psychology of Sport and Exercise, 13(5), 649-657. https://doi.org/10.1016/j.psychsport.2012.04.002

Kim, J., Penney, D., Cho, M., \& Choi, H. (2006). "Not business as usual”: Sport education pedagogy in practice. European Physical Education Review, 12(3), 361-379. 
https://doi.org/10.1177/1356336X06071469

Knowles, M. S. (1970). The modern practice of adult education: Andragogy verus pedagogy. Oxford, England: Association Press.

Lincoln, Y., \& Guba, E. (2005). Paradigmatic controversies, contradictions, and emerging confluences. In N. K. Denzin \& Y. S. Lincoln (Eds.), The Sage handbook of qualitative research (pp. 191-215). Thousand Oaks, CA: Sage Publications Ltd.

Loynes, C. (1998). Adventure in a bun. Journal of Experiential Education, 21(1), 35-39.

Lynch, P., \& Dibben, M. (2016). Exploring motivations for adventure recreation events: a New Zealand study. Annals of Leisure Research, 19(1), 80-97. https://doi.org/10.1080/11745398.2015.1031804

Lyng, S. (1990). Edgework : A social psychological analysis of voluntary risk taking. American Journal of Sociology, 95(4), 851-886. Retrieved from https://www.jstor.org/stable/2780644

Lyng, S., \& Snow, D. (1986). Vocabularies of motive and high-risk behavior: The case of skydiving. Advances in Group Processes, 3(157), 79.

Malterud, K., Siersma, V. D., \& Guassora, A. D. (2016). Sample size in qualitative interview studies: Guided by information power. Qualitative Health Research, 26(13), 1753-1760. https://doi.org/10.1177/1049732315617444

Miller, P., \& Kerr, G. (2002). The athletic, academic and social experiences of intercollegiate student-athletes. Journal of Sport Behavior, 25(4), 346-367.

Morrow, S. L. (2005). Quality and trustworthiness in qualitative research in counseling psychology. Journal of Counseling Psychology, 52(2), 250-260. https://doi.org/10.1037/0022-0167.52.2.250 
Mosston, M., \& Ashworth, S. (2002). Teaching physical education (5th ed.). London: Macmillan.

Mountain Training. (2013). Coaching award scheme. Mountain Training.

Nash, C., \& Collins, D. (2006). Tacit knowledge in expert coaching: Science or art? Quest, 58(4), 465-477. https://doi.org/10.1080/00336297.2006.10491894

Newell, K. M. M. (1991). Motor skill acquisition. Annual Review Psychology, 71(2), 123139. https://doi.org/10.1146/annurev.ps.42.020191.001241

Ojala, A., \& Thorpe, H. (2015). The role of the coach in action sports : Using a problembased learning approach: A case in point , 64-71. https://doi.org/10.1123/iscj.2014-0096

Ong, K., Elliott, B., Ackland, T., \& Lyttle, A. (2006). Performance tolerance and boat set-up in elite sprint kayaking. Sports Biomechanics / International Society of Biomechanics in Sports, 5(1), 77-94. https://doi.org/10.1080/14763141.2006.9628226

Pashler, H., McDaniel, M., Rohrer, D., \& Bjork, R. A. (2008). Learning styles: Concepts and evidence. Psychological Science in the Public Interest, 9(3), 105-119.

https://doi.org/10.1111/j.1539-6053.2009.01038.x

Perdomo, Y. (2014). Global Report on Adventure Tourism. https://doi.org/10.1017/CBO9781107415324.004

Pine, J., \& Gilmore, J. H. (1998). Welcome to the experience. Harvard Business Review, 76(4), 97-105. https://doi.org/Article

Pomfret, G., \& Bramwell, B. (2016). The characteristics and motivational decisions of outdoor adventure tourists: a review and analysis. Current Issues in Tourism, 19(14), 1447-1478. https://doi.org/10.1080/13683500.2014.925430 
Priest, S., \& Gass, M. A. (2005). Effective leadership in adventure programming. Leeds: uman Kinetics.

Robson, C. (2011). Real world research (3rd ed.). Chichester: Wiley.

Sicilia-Camacho, A., \& Brown, D. (2008). Revisiting the paradigm shift from the versus to the non-versus notion of Mosston's Spectrum of teaching styles in physical education pedagogy: A critical pedagogical perspective. Physical Education \& Sport Pedagogy, 13(1), 85-108. https://doi.org/10.1080/17408980701345626

Siedentop, D., Hastie, P. A., \& Van der Mars, H. (2011). Complete guide to sport education. Human Kinetics.

Smith, J. A., Larkin, M., \& Flowers, P. (2009). Interpretative phenomenological analysis: Understanding method and application. London: Sage.

Soderstrom, N. C., \& Bjork, R. A. (2015). Learning versus performance: An integrative review. Perspectives on Psychological Science, 10(2), 176-199. https://doi.org/10.1177/1745691615569000

Sousa, C., Smith, R. E., \& Cruz, J. (2008). An individualized behavioral goal-setting program for coaches. Journal of Clinical Sport Psychology, 2(3), 258-277. https://doi.org/10.1123/jcsp.2.3.258

Super, S., Verkooijen, K., \& Koelen, M. (2018). The role of community sports coaches in creating optimal social conditions for life skill development and transferability-a salutogenic perspective. Sport, Education and Society, 23(2), 173-185. https://doi.org/10.1080/13573322.2016.1145109

Tozer, M., Fazey, I., \& Fazey, J. (2007). Recognizing and developing adaptive expertise within outdoor and expedition leaders. Journal of Adventure Education \& Outdoor 
Learning, 7(1), 55-75. https://doi.org/10.1080/14729670701349780

Turnnidge, J., Côté, J., \& Hancock, D. J. (2014). Positive youth development from sport to life: Explicit or implicit transfer? Quest, 66(2), 203-217. https://doi.org/10.1080/00336297.2013.867275

Valkonen, J., Huilaja, H., \& Koikkalainen, S. (2013). Looking for the right kind of person: Recruitment in nature tourism guiding. Scandinavian Journal of Hospitality and Tourism, 13(3), 228-241. https://doi.org/10.1080/15022250.2013.837602

Vallerand, R. J. (2004). Intrinsic and extrinsic motivation in sport. In Encyclopedia of applied psychology (pp. 427-435). Academic Press. https://doi.org/http://dx.doi.org/10.1016/B0$12-657410-3 / 00835-7$

Varley, P., \& Semple, T. (2015). Nordic slow adventure: Explorations in time and nature. Scandinavian Journal of Hospitality and Tourism, 15(1-2), 73-90. https://doi.org/10.1080/15022250.2015.1028142

Vella, S., Oades, L., \& Crowe, T. (2011). The role of the coach in facilitating positive youth development: Moving from theory to practice. Journal of Applied Sport Psychology, 23(1), 33-48. https://doi.org/10.1080/10413200.2010.511423

Weinberg, R. S. (1994). Goal setting and performance in sport and exercise. Medicine \& Science in Sports \& Exercise, 24(4), 469-477.

Wheaton, B. (2004). Understanding lifestyle sports: Consumption, identity and difference. London: Routledge.

Whiting, L. (2008). Semi-structured interviews: Guidance for novice researchers. Nursing Standard, 22(23), 35-40.

Williams, P., \& Soutar, G. (2005). Close to the "edge": Critical issues for adventure tourism 
operators. Asia Pacific Journal of Tourism Research, 10(3), 247-261.

https://doi.org/10.1080/10941660500309614

Table 1

Summarising the demography of the participants of this study.

\begin{tabular}{llll}
\hline Participant & Gender & Age & Predominant activity, course \\
\hline Natalie & F & 53 & Mountain, Intro to scrambling \\
Brett & M & 42 & Mountain, Lead climber \\
Emma & F & 43 & Mountain, Intro to scrambling \\
Marian & F & 56 & Water, Whitewater kayak improvers \\
Kyle & M & 30 & Mountain, Lead climber \\
Pierce & M & 45 & Mountains, Intro to winter mountaineer / Mountain biking \\
Martin & M & 51 & Mountain, Winter mountaineer \\
Raymond & M & 55 & Mountain, Winter mountaineer \\
Gina & F & 48 & Water, advanced whitewater kayaker \\
Jodi & F & 39 & Mountain, Winter hill walker \\
Justin & M & 35 & Mountain, Winter hill walker \\
Conner & M & 27 & Mountain, Lead climber \\
Simon & M & 46 & Water, Intermediate whitewater \\
Chloe & F & 53 & Water, Intermediate whitewater \\
Alexandre & M & 25 & Mountain, Winter climber skills \\
\hline
\end{tabular}


Table 2

Semi-structured interview questions.

\begin{tabular}{ll} 
Opening Question & Secondary Question \\
\hline $\begin{array}{l}\text { Administration } \\
\text { Have you read and }\end{array}$ & $\begin{array}{l}\text { Signed consent } \\
\text { Do you have any questions at this } \\
\text { information sheet? }\end{array}$ \\
& $\begin{array}{l}\text { stage? } \\
\text { Remind interviewee that they are } \\
\text { free to withdraw at any time } \\
\text { without explanation. }\end{array}$
\end{tabular}

Probes

\section{Recent}

Can you tell me about your most recent coaching session(s)?

What did you get up to?

Ensure ethical

considerations are met

Undefined:

Coaching

Independent adventure

Inspiration

Social group

What did you take from that

Location

coaching?

New independent

adventures

How do you feel as a result?

Enjoyment

Why did you seek out What did you want to achieve?

TTPP

coaching?

What influenced you to seek out

Confidence

Experience

coaching at this point?

Specific challenges

Social groups

Did you have any way of

measuring your improvement/

learning?

Have you used the feedback you were given during this coaching?

What can you/have you done as a result of the coaching?

Do you intend to seek If not, (building on previous

Independence

out coaching again in questions) do you plan to keep

Coach-led experience

the future and why? participating in the sport? i.e.

without coaching are you doing

what you want in your sport? 
If yes, what will be your reason Technical skills for this?

Confidence

More experience

What do you think your goals will NGB courses be?

$\begin{array}{lll}\begin{array}{l}\text { What is your } \\ \text { perception of good } \\ \text { coaching? }\end{array} & \begin{array}{l}\text { What do you expect from the } \\ \text { overall experience? }\end{array} & \begin{array}{l}\text { Quantity of resources } \\ \text { Locations } \\ \text { Warmth of welcome }\end{array} \\ & \begin{array}{l}\text { How did the coach meet your } \\ \text { expectations? }\end{array} & \begin{array}{l}\text { Friendship } \\ \text { Coaching expertise } \\ \text { Teaching skill }\end{array} \\ & \begin{array}{l}\text { How important is having a real } \\ \text { adventure during coaching? }\end{array} & \text { Technical skill } \\ & & \\ & \text { What are your expectations with } \\ \text { long-term learning? }\end{array}$


Table 3

Thematic analysis

\begin{tabular}{|c|c|c|}
\hline $\begin{array}{l}\text { Higher-Order } \\
\text { Themes (3) }\end{array}$ & $\begin{array}{l}\text { Mid-Order Themes } \\
\text { (10) }\end{array}$ & Lower-Order Themes (56) \\
\hline $\begin{array}{l}\text { Holistic } \\
\text { experience }\end{array}$ & Domestic & $\begin{array}{l}\text { Fundamental needs } \\
\text { Good food } \\
\text { Reputation } \\
\text { Comfort }\end{array}$ \\
\hline & Social & $\begin{array}{l}\text { Like-minded people } \\
\text { Socialising } \\
\text { Peer support }\end{array}$ \\
\hline & Packaged & $\begin{array}{l}\text { Enjoyment } \\
\text { Culture surrounding activity/coaching } \\
\text { It's a holiday } \\
\text { Opportunistic } \\
\text { No specific learning outcomes } \\
\text { Safest option for participation } \\
\text { Experience limited to coached experiences }\end{array}$ \\
\hline $\begin{array}{l}\text { Authentic } \\
\text { experience }\end{array}$ & Adventurous & $\begin{array}{l}\text { Real adventure } \\
\text { Adventure provides growth }\end{array}$ \\
\hline & Contextual & $\begin{array}{l}\text { Want to be pushed } \\
\text { Sense of achievement } \\
\text { Learning in context } \\
\text { Controlled environment } \\
\text { Specific to a future goal }\end{array}$ \\
\hline $\begin{array}{l}\text { Developmental } \\
\text { experience }\end{array}$ & Confidence & $\begin{array}{l}\text { Self-efficacy } \\
\text { Self-belief } \\
\text { Overcoming anxiety } \\
\text { Progressive } \\
\text { Affirmation } \\
\text { Ownership } \\
\text { Coach is a source of confidence }\end{array}$ \\
\hline
\end{tabular}




\begin{tabular}{|c|c|}
\hline \multirow{12}{*}{$\begin{array}{l}\text { Technical } \\
\text { development }\end{array}$} & Adaptive skills \\
\hline & Mastery \\
\hline & Control and comfort in actions \\
\hline & Improvement post-course \\
\hline & Step/jump in improvement \\
\hline & Faster rate of progression post-course \\
\hline & Fundamentals \\
\hline & Simpler \\
\hline & To correct bad habits \\
\hline & Technical development \\
\hline & Competency \\
\hline & Training for emergency \\
\hline \multirow[t]{5}{*}{ Independence } & Seeking independence \\
\hline & Independence is necessary \\
\hline & Independent post-course \\
\hline & Decision-making \\
\hline & At times not independent during the course \\
\hline \multirow[t]{11}{*}{ Learning capacity } & Continuously learning \\
\hline & Consolidation \\
\hline & Value of practice \\
\hline & More experience needed \\
\hline & Framing \\
\hline & Feedback \\
\hline & Social learning \\
\hline & Declarative knowledge \\
\hline & Learning from the coach's experience \\
\hline & Takes notes \\
\hline & Top tips and handy hints \\
\hline
\end{tabular}

